NBER WORKING PAPER SERIES

SIMULATING NONLINEAR TAX RULES AND NONSTANDARD

BEHAVIOR: AN APPLICATION TO THE TAX TREATMENT

OF CHARITABLE CONTRIBUTIONS

\author{
Martin Feldstein \\ Lawrence Lindsey \\ Working Paper No. 682
}
NATIONAL BUREAU OF ECONOMIC RESEARCH
1050 Massachusetts Avenue
Cambridge MA 02138

May 1981

This paper was presented at the NBER Conference on Behavioral Simulation Methods in Tax Policy Analysis on January 26-27, 1981, in Palm Beach. The research reported here is part of the NBER's research program in Taxation, and project in Tax Simulation. Any opinions expressed are those of the authors and not those of the National Bureau of Economic Research. 


\section{Summary \\ Simulating Nonlinear Tax Rules and Nonstandard Behavior \\ An Application to the Tax Treatment of Charitable Contributions}

This paper examines how the tax simulation method can be extended to incorporate nonlinear budget constraints and nonstandard economic behavior. We simulate the effect of extending the charitable deduction to nonitemizers and study the effect of alternative "floors".

The specific simulations indicate that the econometric evidence on charitable giving implies that extending the charitable deduction to nonitemizers would raise individual giving by about 12 percent of the existing total amount or $\$ 4.5$ billion at 1977 levels. The extension would reduce tax revenue by slightly less, about $\$ 4.1$ billion. A floor of $\$ 300$ or 3 percent of AGI would reduce the revenue loss by 30 to 40 percent, even if there is significant bunching. The effect of the floor on increased giving depends critically on whether taxpayers' behavior is guided by conventional demand principles or by the net altruism rule. A reasonable conclusion is that a floor would reduce giving by less than the increased revenue but that the difference between them would not be very large.

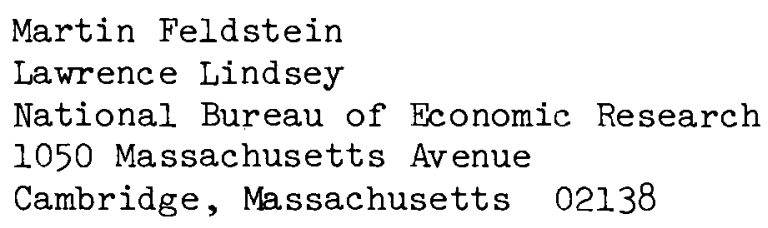

(617) 868-3905 
Simulating Nonlinear Tax Rules and Nonstandard Behavior An Application to the Tax Treatment of Charitable Contributions

\author{
Martin Feldstein* \\ Lawrence Lind sey*
}

The effect of existing tax rules on charitable contributions has been the subject of several econometric studies in recent years.I The present paper uses the results of those studies as the basis for examining the potential effects of alternative tax rules that might be applied in extending the charitable deduction to nonitemizers. 2 Our focus is on the effect that such changes in tax rules would have on charitable contributions, on tax liabilities, and on the distribution of these effects by income class.

Our methodological emphasis is on simulating behavioral responses to nonlinear tax rules, e.g., a rule that allows nonitemizers to deduct charitable gifts in excess of $\$ 300$ per year. We examine three types of response to such nonlinear rules. The first is based on conventional demand analysis with a nonlinear budget constraint. The second recognizes that individuals have an

* Martin Feldstein is Professor of Economics at Harvard University and President of the National Bureau of Economic Research. Lawrence Lindsey is a Teaching Fellow at Harvard and a Research Analyst at the National Bureau of Economic Research. They are grateful to the members of the Tax Simulation Project, and especially to Daniel Feenberg and Daniel Frisch, for helpful discussions, to the NBER and National Science Foundation for support of this research, and to Harvey Galper for valuable comments on the previous version. The views expressed here are the authors' and should not be attributed to any organization.

1 See Boskin and Feldstein (1977), Clotfelter (1980), Clotfelter and Steuerle (1980), Feldstein (1975), Feldstein and Clotfelter (1976), Feldstein and Taylor

2 A variety of proposals to extend the charitable deduction have been made over the years, especially when other tax changes reduce the fraction of taxpayers who itemize their personal deductions. One recent proposal is contained in the bill introduced in the House of Representatives by Congressmen Fisher and Moynihan and Packwood (S. 219, 96th Congress, 2nd session). For a copy of the bill and further analysis, see "Hearings before the Subcommittee on Taxation and Debt Management generally and the Committee on Finance, United States Senate, January 30 and 31 , 1980." 
incentive to respond to a floor by "bunching" their contributions over time, e.g., by contributing only in alternate years to reduce the fraction of total contributions that are below the floor and therefore that do not receive the tax benefit. The third approach departs from the usual utility maximization model of demand to consider a quite different type of altruistic behavior that may be appropriate for studying charitable contributions. The essential feature of this approach is that it assumes each individual wishes to make charitable gifts with some fixed net-of-tax cost; changes in tax rules alter the gross amount of giving to maintain this net cost.

All three approaches are generally consistent with the available statistical evidence. The behavior of taxpayers under existing rules does not allow a choice among the three models; in statistical terms, the model is underidentified. This underidentification does not affect predictions of the effects of alternative linear tax mules, e.g., substituting a credit for the existing deduction. Although the predicted effects of an alternative linear tax rule does not depend on which of the three models is assumed to be correct, 3 with nonlinear tax rules the three models can have very different implications. Predictions of the effects of nonlinear tax rules must therefore be regarded as conditional on the model specification and any user of our analysis must "weight" these conditional predictions by his own subjective probabilities of the appropriateness of the model.

3. The choice between the third model and the first two does have some effect on the estimated response to changes in tax rules, but the size of the effect is relatively small. 
The simulations are all made with the National Bureau of Economic Research TAXSIM Model. This computerized model, like the one used by the Treasury and the Joint Committee on Taxation, bases its calculations on the large stratified random sample of individual tax returns that are provided for this purpose by the Internal Revenue Service. But unlike these other models, the NBER TAXSIM model is specifically designed to take into account the response of taxpayer behavior to changes in tax rules. 4 The version of the model used in the present paper is based on the tax law for 1977 and uses a sample of 23,111 individual tax returns for that year. 5

The first section of the paper summarizes the previous econometric evidence on charitable giving that forms the basis for the parameter values used in the current simulations. Section 2 describes the alternative tax rules and the three models of behavior that will be simulated. Some technical aspects of the simulation procedure, including the imputation of contributions to nonitemizers and the calculation of the effective cost of charitable gifts, are discussed in section 3. The simulation results are presented in sections 4 and 5 . There is a brief concluding section.

4 The economists who have participated in the development of the TAXSIM model are Daniel Feenberg, Martin Feldstein, Daniel Frisch, Larry Lindsey, and Harvey Rosen.

5 These 23,11l returns are a random 25 percent sample of the 1977 Treasury Tax Model Public Use Sample. 


\section{Econometric Evidence on Charitable Giving}

Since this paper will not present any new econometric evidence on charitable giving, it is useful to review the previous econometric research. The current tax law allows any taxpayer who itemizes his deductions to subtract the value of charitable contributions in calculating taxable income. The "price" of one dollar's contribution to a charitable organization in terms of the foregone disposable income of the donor therefore varies inversely with his marginal tax rate. Of course, for anyone who does not itemize his deductions, the price of one dollar's contribution is one dollar of foregone disposable income. 6

The key parameter that determines the effect of the existing charitable deduction and of alternative linear tax rules is the price elasticity, i.e., the elasticity of the individual's gross (pretax) charitable gift with respect to the price of giving. The appropriate value is of course the partial elasticity, holding constant the level of income and such other demographic characteristics that might be associated with the price. Several studies in recent years, based on quite different bodies of data, have concluded that the price elasticity of giving is between -1.0 and -1.5 . There is a striking degree of consistency and relative precision in these estimates even though they are based on different years and different types of data.

Feldstein (1975) used the data published by the Internal Revenue Service on the mean level of charitable giving and the mean level of disposable income

6 This ignores the special problem of gifts of appreciated property, a subject to which we return later. 
in each of 27 adjusted gross income (AGI) classes for the alternate years between 1948 and 1968. These data refer only to individuals who itemized their deductions. A constant elasticity specification was estimated:

$$
\ln G_{i t}=b_{0}+b_{1} \ln P_{i t}+b_{2} \ln Y_{i t}+e_{i t}
$$

where $G_{i t}$ is the mean charitable gift of individuals in AGI class $i$ in year $t$, $P_{i t}$ is the price calculated at the mean taxable income in that class, and $Y_{i t}$ is the mean disposable income in that class. The changing tax rates as well as the differences in the rates among classes were used to estimate the price elasticity. The basic estimate in this study, with the sample restricted to taxpayers whose AGI's were between $\$ 4,000$ and $\$ 100,000$ at 1967 prices, was -1.24 with a standard error of 0.10 . Including all income classes in the sample raised the elasticity to -1.46 with a standard error of 0.08 .

Feldstein and Clotfelter (1976) used individual household data collected by the Census Bureau in 1963 and 1964 for the Federal Reserve Board's Survey of Financial Characteristics of Consumers. Their sample of 1,406 individuals provided information on wealth and demographic characteristics as well as on income and charitable giving. The data made it possible to estimate for each household the price of charitable giving and a measure of disposable income defined as the total income received minus an estimate of the tax that would be due if no contribution were made. The basic price elasticity estimate in this study was -1.15 (standard error 0.20). Several variants of the basic equation showed that the estimated price elasticity was not sensitive to the measurement of permanent income or the inclusion of a variety of other demographic and economic characteristics. 
Feldstein and Taylor (1976) used a similar specification to study a sample of more than 15,000 taxpayers who itemized their deductions and whose tax returns were included in the 1970 Treasury Tax File, a stratified random sample of individual tax returns. The basic price elasticity estimate was -1.29 (standard error 0.06). Repeating this calculation for the 1962 Treasury Tax file data showed a price elasticity of -1.09 (standard error 0.03). A price elasticity estimate based on the change in the tax schedule between 1962 and 1970 was -1.39 (standard error 0.19).

Similar estimates were obtained in several other studies using different sets of microeconomic data. Reece (1979) used the 1972-73 Consumer Expenditure Survey of the BIS and estimated a price elasticity of -1.19 using a Tobit estimating procedure. Dye (1977) studied a 1974 Michigan Survey Research Center survey of households with incomes under $\$ 50,000$ and estimated a price elasticity of -2.25. Clotfelter and Steuerle (1979), using tax data for 1975, estimated a price elasticity of -1.25. And Clotfelter (1980), using the unstratified random sample of tax returns for 1972, obtained a price elasticity of -1.40 .

These estimates refer to the entire population or to all taxpayers who itemized and not to any particular income class. The present analysis of the potential effect of extending the charitable deduction to those who do not currently itemize their deductions makes it particularly important to have an estimated price elasticity for middle and lower income households; more than 90 percent of 1977 nonitemizers had adjusted gross incomes of less than \$20,000. Although separate estimates for each income class cannot be made as precisely as for the sample as a whole, the evidence generally indicates that the relevant elasticity for this group is as high as for the population as a whole. 
The pooled data by year and income class (Feldstein, 1975) was analyzed in separate regressions for different income groups. For the 64 observations with mean real income (in 1967 dollars) between $\$ 4,000$ and $\$ 10,000$, the estimated price elasticity was -1.80 (standard error $=0.56$ ). Among taxpayers with real incomes between $\$ 10,000$ and $\$ 20,000$, the corresponding estimate was -1.04 (standard error $=0.76$, with 27 observations).

Despite the small samples, these data had the advantage of tax schedules that varied over time. When attention is limited to a single cross section of individual data, it is more difficult to estinate separate equations in each income class. This is particularly true in the low and middle income classes where there is a very high correlation between income and tax rates. 7 It is nevertheless possible to allow the estimated price elasticity to vary with income or marginal tax rate while estimating the other parameters from the entire sample.

The Feldstein and Clotfelter (1976) study found that the price elasticity was greatest for those with the highest "price of giving"; the estimated elasticity was -1.82 (with a standard error of 0.64 ) for those with a price of giving in excess of 0.7 and then fell to -1.26 (s.e. $=0.42$ ) for those with a price between 0.3 and 0.7 and to -1.16 (s.e. $=0.20$ ) for those with a price below 0.3 . The differences are not statistically significant but, if anything, provide evidence that the current nonitemizing population has a higher elasticity.

The Feldstein and Taylor (1976) study had a much larger sample and could

7 In higher income classes, there is much more variation in tax rates at each level of adjusted gross income as well as substantial income variation within tax brackets. 
therefore obtain estimates with smaller standard errors. The estimated price elasticities varied inversely with income, from -2.26 (s.e. $=0.42$ ) for taxpayers with incomes below $\$ 10,000$ and -1.82 (s.e. $=0.24$ ) for taxpayers with incomes between $\$ 10,000$ and $\$ 20,000$ to -1.17 (s.e. $=0.09$ ) for those with incomes between $\$ 50,000$ and $\$ 100,000$ and $-1.27(\mathrm{~s} . \mathrm{e}=0.06)$ for those with incomes over $\$ 100,000$. An analogous equation for 1962 is not reported. Estimates of separate price and income elasticities in each income class give implausible values for the lowest income class (those with AGI between $\$ 4000$ and $\$ 20,000):-3.67($ s.e. $=0.45)$ for 1962 and $-0.35($ s.e. $=0.52)$ for 1970 .

In a separate study designed to measure the price elasticity for the lower and middle income groups, Boskin and Feldstein (1977) used survey data collected in 1974 by the University of Michigan Survey Research Center on households with incomes below $\$ 30,000$. Because these are survey data rather than tax return data, they contain information on contributions by nonitemizers as well as itemizers. This provides much more price variation at each income level. The Boskin-Feldstein analysis estimated a price elasticity of -2.54 (s.e. = 0.28) for this group. An additional analysis of these data showed that the difference between itemizers and nonitemizers could be explained completely by the price effect without recourse to a separate "itemization" effect.

Clotfelter and Steuerle (1979) estimated a variety of different specifications for separate income classes using the Treasury Tax Model for 1975. They found that the estimated results in the lower income class were quite sensitive to the particular specification. The basic logarithmic equation implied price elasticities of -0.9 for incomes of $\$ 4,000$ to $\$ 10,000$ and -1.3 for incomes of $\$ 10,000$ to $\$ 20,000$. Estimating a single equation for all income classes but 
using a more general functional form implied lower price elasticities; the estimates ranged between -0.4 and -0.7 . But constraining the coefficient to be the same for all income classes reverses this effect and implies price elasticity of -2.2 and -1.4 . In our view, this sensitivity shows the difficulty of trying to infer separate elasticities for low and middle income groups.

Before turning to the simulations, it is useful to consider the plausibility of a price elasticity between 1 and 2 for a typical nonitemizing family. In 1977 , families with adjusted gross incomes between $\$ 10,000$ and $\$ 15,000$ who itemized their deductions gave an average of \$522. If such a family had a taxable income of $\$ 8000$, the price per dollar of giving would be approximately 80 cents. A price elasticity of -1.0 and a price of 0.80 imply that deductibility raises giving by 25 percent; i.e., by $\$ 104$ from $\$ 418$ to $\$ 522$. Similarly, a price elasticity of -2.0 would imply that deductibility raised giving by 56 percent or by $\$ 188$ from $\$ 334$ to $\$ 522$. Changes of this magnitude are not contrary to intuition or to any other evidence.

To be conservative, the estimates developed in this paper will generally be based on a price elasticity of -1.3 . Some additional estimates using price elasticities of $-0.7,-1.0$ and -1.6 will also be presented.

\section{Extending the Contribution Deduction to Nonitemizers}

The basic proposal to be analyzed in this paper allows all taxpayers to deduct charitable contributions in the calculation of taxable income. More specifically, taxpayers who itemize other deductions would continue to include charitable contributions as part of deductions as they presently do. Taxpayers who do not itemize other deductions would be allowed to subtract their chari- 
table contribution from gross income in the same way that they now subtract an amount for each exemption. In this way, there is no change in adjusted gross income or in any of the amounts that depend on it.

This basic scheme might be modified by limiting the charitable deduction of nonitemizers to the excess over some dollar amount or some percentage of the taxpayers adjusted gross income. A rationale for such a "floor" is that the standard deduction implicitly recognizes some minimal or typical charitable gift so that individuals should get an explicit deduction only for the excess over that amount. 8 An alternative rationale for a floor is that it can reduce the loss of tax revenue and, to the extent that contributions exceed the floor amount, the reduction in revenue loss would have no impact on the marginal incentive to give. For example, in 1977 taxpayers with AGI's between $\$ 15,000$ and $\$ 20,000$ who did not itemize made charitable gifts averaging nearly $\$ 400$. For someone giving an average amount, a $\$ 300$ floor would have no effect at the margin on the incentive to give. The current paper analyzes two alternative floors: the first is $\$ 300$ and the alternative is 3 percent of adjusted gross income (AGI).

\subsection{The Conventional Demand Model}

The effects of extending the charitable deduction to nonitemizers, and particularly the effects of the floors, depends on the type of individual behavior that is assumed. The most basic behavioral assumption, and the one that

8 The logic of that argument is hardly compelling. If the charitable deduction is extended to nonitemizers, it would be more appropriate to reduce the standard deduction by the currently assumed amount of the "typical" gift and then allow all individuals the full amount of their deduction. 
underlies the specification of the econometrically estimated equations, is that individual giving responds to a change in price according to the constant elasticity formula:

$$
G_{1}=G_{0}\left(P_{1} / P_{0}\right)^{\alpha},
$$

where $G_{1}$ is the level of annual giving after the "reform," $G_{0}$ is the level of annual giving before the reform, $9 \mathrm{P}_{0}$ is the price before the reform, ${ }^{10} \mathrm{P}_{1}$ is the price after the reform, and $\alpha$ is the price elasticity of denand. There is no need to adjust separately for the change in disposable income since the estimated price elasticity includes the income effect as well as the substitution effect; i.e., the initial econometric equation defines the disposable income as AGI minus the tax that would be due if the individual made no charitable contribution.

More specifically, equation 2 describes what is essentially the response of nonitemizers (i.e., those who under existing law are nonitemizers) when they are allowed to deduct charitable gifts. For most itemizers, the proposal involves no change in behavior. However, about 6 percent of current itemizers would cease to itemize if they could then deduct their charitable contributions; i.e., their itemized deductions excluding charitable contributions is less than

9 The method of imputing an initial level of giving for nonitemizers is discussed in section 3 of this paper.

10 For nonitemizers, $P_{0}$ differs from one only because of gifts of appreciated property. This difference is discussed in section 3. Although as a practical matter, the difference from one for this group is small enough to ignore completely, our price calculations do reflect for each individual the average percentage of appreciated property in total contributions. 
the standard deduction to which they would be entitled.11 For most of these "switchers" there is no change in marginal tax rate and therefore no change in price. However, since an individual only switches if his tax bill is reduced, there is a small income effect. The giving of a switcher can be calculated according to the equation:

$$
G_{1}=G_{0}\left(P_{I} / P_{0}\right)^{\alpha}\left(Y_{I} / Y_{0}\right)^{\beta},
$$

where $\mathrm{Y}_{O}$ is the initial value of total income minus the tax liability if the individual made no contribution and $Y_{1}$ is the corresponding value if the individual stops itemizing and uses the standard deduction. 12 The difference between $Y_{1}$ and $Y_{0}$ is the tax that the individual saves by switching from itemizing to using the standard deduction, given that the charitable contribution is deductible in any case.

Although the demand behavior implied by equation 2.1 is adequate for estimation and for simulating alternative linear budget constraints, it is inadequate for analyzing alternative nonlinear budget constraints. Figure 1 illustrates the nature of this problem in a simple case. The standard deductor initially faces a budget line UVW with a slope of -1 between giving $(G)$ and other spending $(C)$. He chooses point $E_{1}$. Allowing standard deductors to take an additional deduction for charitable gifts above a floor (F) puts a kink in the budget line which becomes UVX.

11 In 1977, the standard deduction was $\$ 3200$ for a married couple and $\$ 2200$ for a single individual.

12 An income elasticity of 0.7 is used in the calculations; see Feldstein and Taylor (1976) for supporting evidence. Because the relevant income changes are always very small, the results are very insensitive to the choice of this elasticity. 
Figure 1

Alternative Response to Deductibility

above a Floor

G
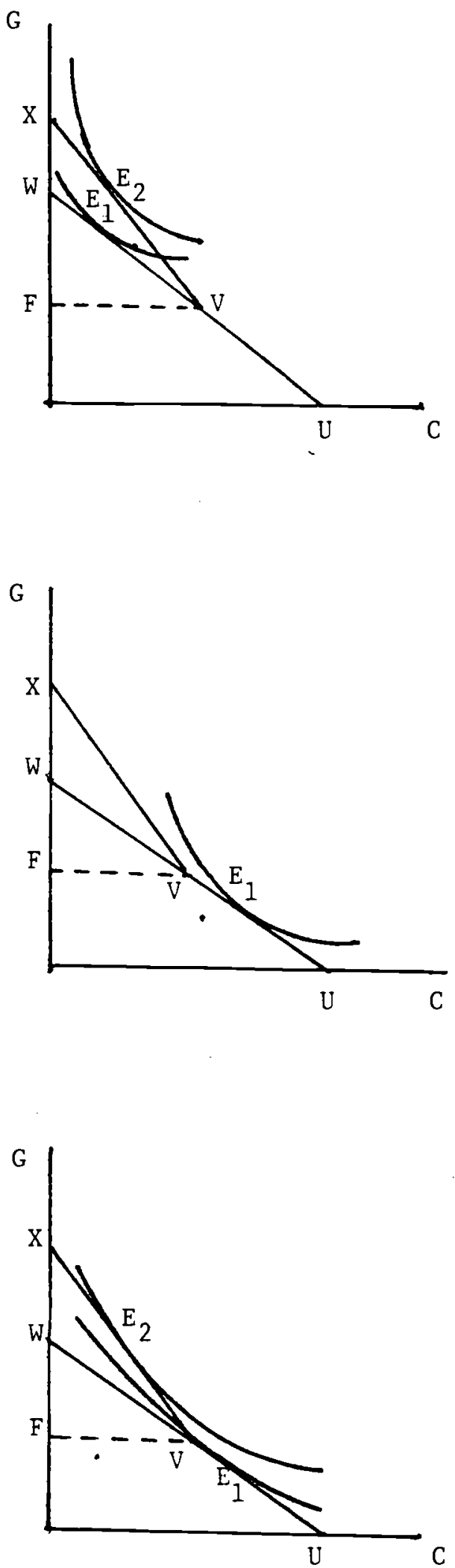

Figure 1A

Figure 1B 
In the case shown in Figure 1A, the individual was giving more than the floor even without the deduction. For such an individual, the deductibility with a floor is equivalent to an ordinary price change except for an offsetting negative income effect equal to $\mathrm{mF}$ where $\mathrm{m}$ is the individual's marginal tax rate. This case could therefore be analyzed using the demand function of equation 2.2 with appropriate definitions of $P_{1}$ and $Y_{1}$.

In the case shown in Figure 1B, the individual was giving less than the floor. The change in the budget constraint therefore occurs in an irrelevant section of the budget constraint and the individual continues to give at Ei. This could also be analyzed using the demand function, since the price is unchanged for this individual.

But the choice in figure $1 \mathrm{C}$ cannot be analyzed with the demand function. The individual initially gives an amount less than the floor $F$. But the individual's indifference curve cuts the new branch of the budget constraint, implying that the individual's optimum point is on the new branch. This can only be determined by an explicit utility comparison.

In order to be able to deal with situations like figure $1 \mathrm{C}$, we therefore continue the analysis with the help of an explicit utility function that implies the constant elasticity demand structure of equation 2.2. We follow Hausman (1979) and write the indirect utility function of individual $i$ as:

$$
v_{i}(p, y)=-k_{i} \frac{p^{1+\alpha}}{1+\alpha}+\frac{y^{1-\beta}}{1-\beta}
$$

This indirect utility function implies a demand function with constant price elasticity $\alpha$ and constant income elasticity $\beta$. Since existing law provides a 
linear budget constraint for small changes in giving, 13 we can use the price and income elasticities estimated in previous studies with equation 2.1 to parametize this utility function. The value of $k_{i}$ for individual $i$ can then be calculated as the value which causes the demand for giving implied by equation 2.3 for individual $i$ to equal the actual observed amount of giving.

With the help of such a parametized indirect utility function for each individual, we proceed in the following way to calculate the value that each individual would give if nonitemizers could deduct gifts in excess of floor F. (To simplify the description of our procedure, we now ignore gifts of appreciated property and the possibility that giving causes the individual to change tax brackets. 14)

First, if the initial giving of individual $i\left(G_{O i}\right)$ exceeds the floor $(F)$, we can use equation 2.3 to calculate the new level of giving by reducing the price from $l$ to $1-m_{i}$ (where $m_{i}$ is the individual's marginal tax rate and by lowering the individual's income by $m_{i} F$. We then use these values to calculate the new level of giving, Gli. This corresponds to figure 1A.

If $G_{0 i}$ is less than the floor, we consider first the potential reaction if the individual faces the reduced price above the floor. If with this price (and the associated income correction) the implied giving is still less than the floor, we know we are in case $1 B$ in which giving is unchanged. If however, the implied giving is greater than the floor, we are in case $\mathrm{C}$ and must

13 There is a nonlinearity for the few individuals whose giving causes them to switch brackets or to move from nonitemize to itemize. Ignoring the switch from nonitemizer to itemizer biases the estimated price elasticity toward zero.

14 The full computer program recogizes both of the possibilities. The method of dealing with property gifts is discussed in Section 3. Changes in tax brackets are reflected by using the new marginal price and changing the initial level of income. 
choose between the possibilities by comparing the implied utilities. Conditional on the assumption that the individual will not change his giving (i.e., will remain at $E_{1}$ in figure $1 C$ because the indifference curve tangent to the new section of the budget line is lower than the indifference curve tangent at $\mathrm{E}_{1}$ ), we evaluate the utility at the initial price $\left(p_{i}=1\right)^{15}$ and unchanged income, say $\mathrm{V}_{\mathrm{O}}$. Then, conditional on the assumption that the individual increases his giving (i.e., moves to point $E_{2}$ in figure $1 C$ ) we take $p_{i}$ to be the itemized price $\left(P_{i}=1-m_{i}\right.$, except for gifts of appreciated property) and reduce income by $m_{i} F$. This implies an increased value of giving $G_{1 i}$ and an associated utility value $V_{l i}$. The choice between the two points is then done by comparing $V_{0 i}$ and $V_{1 i}$ for the individual.

An analogous calculation is used to analyze the possibility that an individual who is currently an itemizer might switch to using the standard deduction if he could continue to itemize his charitable gifts. To decide whether to switch, the individual compares his utility level as an itemizer with the utility level that he would achieve as a nonitemizer who can deduct his charitable giving. In practice, about 6 percent of current itemizers would find that it is desirable to use the standard deductions when charitable gifts become eligible for a separate deduction.

\subsection{The Bunching of Gifts}

The use of a floor provides an incentive for individuals to "bunch" their charitable giving. With a $\$ 300$ floor, a nonitemizer who gives $\$ 300$ each year would get no tax reduction. By giving $\$ 600$ every other year, the indivi-

\footnotetext{
15 In the actual calculations, $p_{1}$ is lower than one because of gifts of appre-
} ciated property. 
dual would also have a $\$ 300$ tax deduction every other year, or a 50 cent deduction per dollar of contribution. And by giving $\$ 900$ every third year, the deduction would rise to 67 cents per dollar of gift. Although the 'logical' extreme is of course implausible because of the resulting effect on the individuals' marginal tax rates and because individuals and institutions both have reasons to favor a steady flow of giving, the presence of a floor seems very likely to lead to some bunching.

There is, unfortunately, no experience with charitable deduction floors that can be used to estimate thier likely effect on bunching. We have however constructed two alternative simulation models and tested the parametric sensitivity of the results.

Both models assume that the extent of bunching depends on the potential tax saving from bunching and therefore on both the size of the contribution and the individual's marginal tax rate. In both models, the possibility of bunching is limited to a two year cycle. The first model assumes that each individual bunches either all of his contributions or none. That is, if he is a "buncher," he gives only in alternate years. The probability of being a buncher depends on the tax incentive. The second model assumes that everyone is a "partial buncher;" some fraction of his total giving is bunched (i.e., given only in alternate years) while the rest of his contribution is given every year. We will now describe these models as they apply to someone who is currently a nonitemizer. 16

16 For itemizers, the possibility of switching is again evaluated by comparing the tax liability as an itemizer with the tax liability as a nonitemizer, but this time including the effect of bunching. 
The tax incentive to bunch is a function of the relative cost of giving with and without bunching. Let $G_{1 i}$ be the amount that individual $i$ (a nonitemizing taxpayer) would give if charitable gifts in excess of a floor could be deducted. 17 Let $\mathrm{CG}_{1 i}$ be the net cost to individual $i$ of making this charitable gift in a single year, i.e., without bunching. $C^{C} G_{1 i}$ is equal to $G_{l i}$ reduced by the tax saving associated with the contribution, i.e., the tax saving that results from deducting the excess of $G_{1 i}$ over the floor. Similarly, let $\mathrm{BCG}_{1 i}$ be the net cost of making this charitable gift by bunching two years' gifts into a single year. 18 We assume that the propensity to bunch depends on the ratio of these net costs: $B C G / C G$.

More specifically, the first model assumes that the probability that individual $i$ will bunch is given by

$$
\mathrm{PROB}_{i}=1-\left(\mathrm{BCG}_{1 i} / \mathrm{CG}_{1 i}\right) \rho
$$

with $\rho>0$. Note that under current law, with no floor, there is no incentive to bunch $19: \quad B C G=C G$ and $P R O B=0$. However, a floor on the charitable deductions implies $\mathrm{BCG}<\mathrm{CG}$ and therefore $\mathrm{PROB}>0$. The greater the value of $\rho$, the more sensitive is the probability of bunching to the relative cost. To appreciate the order of magnitude of this effect, consider a taxpayer who would contribute 400 dollars without bunching $\left(G_{1 i}=400\right)$ and whose marginal tax rate

17 The calculation of $G_{1 i}$ was described in Section 2.1.

18 This is calculated by finding the tax reduction associated with contributing $2 G_{1 i}$, i.e., the tax saving that results from deducting the excess of $2 G_{1 i}$ over the floor, and then subtracting half of this tax saving from $G_{1 i}$.

19 This assumes that the individual connot predict year-to-year changes in his marginal tax rate. In fact, there is some predictable variation and therefore some incentive to bunch. Although we believe this is likely to be small, some investigation with the longitudinal tax rule would be worthwhile. 
is 30 percent. With a 300 dollar floor, the cost of giving is 370 dollars with no bunching and 325 dollars with bunching. Thus $\mathrm{PROB}=1-(325 / 370)^{\rho}=1-$ (0.88) $\rho$. If $\rho=2, \mathrm{PROB}=0.23$ while $\rho=0.5$ implies $\mathrm{PROB}=0.06$ and $\rho=10$ implies $\mathrm{PROB}=0.73$. Since econometric evidence about $\rho$ is unavailable, the simulations show the sensitivity of the conclusions to alternative values of $\rho$.

of course, those individuals who bunch change the amount of their gift because of bunching. If, without bunching, the individual's gift would be below the floor while bunching makes the gift (in the year in which it is given) greater than the floor, there is a reduction in the price of giving and therefore an incentive to give more. Among those whose gift would be above the floor without bunching, bunching has a positive income effect on the amount of the gift.

In general, a floor reduces the loss of tax revenue that results from extending the deduction to nonitemizers and reduces also the incentive to give associated with such an extension. Bunching increases the revenue loss but, unless there is complete bunching, still leaves a smaller revenue loss than with no floor. However, even with bunching the incentive to give is not as great as without a floor. Whether the floor raises or lowers the tax revenue "loss" per dollar of induced extra giving is an empirical question that we will examine in section five with the help of the simulations.

The alternative "partial bunching" model assumes that all taxpayers bunch some of their giving if there is a floor and that the extent of bunching depends on the cost ratio, $B C G / C G$. The idea of partial bunching is based on the asymmetry of information between donors and donees. Much giving is done in response to requests for contributions and is done in a way that the donee orga- 
nization and others know the amount of the donor's gift. The individual who responds to a request for a contribution by saying "I give every other year and this is my off year" may not be credible. Individuals may also prefer to appear more generous, especially for relatively small amounts, by appearing to ignore tax considerations. And making a contribution may seem better than trying to explain the tax law to the sellers of Girl Scout cookies or Little League decals.

We assume that the specific incentive to partial bunching is of the same form as equation 2.4 :

$$
\mathrm{PROP}_{i}=1-\left(\mathrm{BCG}_{1 i} / \mathrm{CG}_{1 i}\right)^{\rho},
$$

where $\mathrm{PROP}_{i}$ is the proportion of the charitable gift that individual $i$ bunches. The amounts of the gifts in the "low" and "high" giving years depends on the interaction between bunching, floors and tax saving. For example, if (1 PROP $\left._{i}\right) G_{1 i}$ is greater than the floor, bunching does not change the price of giving in either year but does have an income effect that raises giving to (say) $\mathrm{G}_{2 i}$. In this case, the individual gives $\left(1-\mathrm{PROP}_{i}\right) \mathrm{G}_{2 i}$ in the low year and $(1+$ $\left.\mathrm{PROP}_{i}\right) \mathrm{G}_{2 i}$ in the high year. Alternatively, if $\mathrm{G}_{1 i}$ is less than the floor but $\left(1+\mathrm{PROP}_{i}\right) G_{1 i}$ exceeds the floor, there are both price and income effects in the "high" year but only an income effect in the "low" year. We assume that in the "high" year the individual in this case gives $\left(1+\mathrm{PROP}_{i}\right) \mathrm{G}_{1 i}\left(\mathrm{P}_{1} / \mathrm{P}_{0}\right)^{\alpha}\left(\mathrm{Y}_{1} / \mathrm{Y}_{0}\right)^{\beta}$ where $P_{1}$ reflects the marginal deductability and $Y_{1}$ differs from $Y_{0}$ because of the effects of the floor (which lowers $Y_{1}$ ) and the bunching (which raises $Y_{1}$ ). Although the income-effect adjustments are not precise, they are relatively 
small and further elaborations or refinements have no significant effects. 20

There is one further aspect of the partial bunching model that deserves comment. In the case in which giving without bunching substantially exceeds the floor, the equation that describes partial bunching might still leave giving in both years at levels above the floor. Since in that case there is no gain from bunching, we assume that the proportion bunched is actually zero.

The difference between the effects of the two models of bunching depends on the taxpayer's initial situation. There are cases in which partial bunching would save no tax and have no effect on giving while total bunching would do both. There are other cases in which partial bunching would have a larger total effect on both giving and tax receipts. The net balance is examined in section 5 with the help of the simulations.

\subsection{Net A.ltruism}

Although charitable giving can be modelled like other types of consumer spending, it is worth considering the possibility that charitable behavior is actually "different." Individuals may make charitable gifts because of a sense of responsibility, religious devotion, altruism, guilt, or other considerations that may cause behavior to differ from traditional utility maximization. We emphasize "may" because, even with these motivations, actual charitable giving might behave just as traditional theory predicts. Certainly the normal price and income elasticities found in the econometric studies are consistent with this.

But individuals might think about charitable giving in terms of their desire to "sacrifice" or to contribute their "fair share" rather than in terms 
of the benefits that they can achieve for the donee organization. In this case, the deductibility of charitable gifts has the effect of reducing the donor's "sacrifice" or "net contribution." To achieve the initial level of sacrifice, the donor must increase the size of his contribution. If the individual wishes to make a fixed sacrifice regardless of the tax law, full deductibility (with no floor) causes the individual to behave as if he had a price elasticity of -1 ; that is, $G_{1}=G_{0}\left(P_{1} / P_{0}\right)^{-1}$ since this implies a constant net cost of giving, $P_{1} G_{1}=P_{0} G_{0}$.

Although the econometric evidence suggests that the price elasticity is absolutely larger than one, the possibility of a price elasticity of minus one cannot be ruled out. If the observed price elasticity were minus one, the available evidence could not be used to distinguish between the traditional demand model and the alternative "net sacrifice" or "net altruism" model. With no floor, the two models are observationally equivalent.

The presence of a floor causes a substantial difference between the conventional demand model (with a price elasticity of minus one) and the "net altruism" model. Consider an individual who, with no deductibility, contributes $\$ 400$ and whose marginal tax rate is 30 percent. The net cost to such an individual is $\$ 400$. Allowing deductibility with no floor causes the contribution to rise to $400(0.7)^{-1}=571$ dollars. With a 300 dollar floor, the conventional model predicts that giving will fall short of 571 dollars only because of a small income effect; the extra tax of 90 dollars caused by the floor would reduce giving by about 5 dollars. But the 300 dollar floor implies that the "net altruist" must give substantially less than 571 dollars to maintain the original 400 dollar net cost. In particular, a total gift of 443 dollars would have a net cost of 400 dollars. 
The possibility that individuals decide on the basis of total net cost rather than marginal net cost implies that a floor does not reduce the loss in tax revenue per dollar of induced additional giving. In the example of the previous paragraph, deductibility with no floor would cause giving to rise by 171 dollars and tax revenue to fall by 171 dollars $(0.3 \times 571)$. Deductibility with a 300 dollar floor would cause giving to rise by 43 dollars and tax revenue to fall by 43 dollars $(0.3 \times 143)$.

The implications of the "net altruism" model will be considered as part of the simulations in section 5 .

\section{Some Technical Aspects of the Simulation Procedure}

As we noted in the introduction to this paper, our simulations use the NBER TAXSIM model with the 1977 tax law. Our sample of 23,111 returns is a onein-four random sample from the Treasury's Public Use File of 1977 tax returns. In simulating the effect of any tax change proposal, we use the model to calculate consistent values for each individual of the price of giving under the new law, the amount that that individual gives, and the individual's new tax liability. The entire TAXSIM model with all features of the tax code are used in these calculations. By using the sampling weights provided by the Treasury, we can then aggregate the individual changes in giving and in tax liabilities to obtain estimates for all taxpayers and for taxpayers in each income class.

Two technical issues in the simulation deserve special attention: (1) the calculation of the price of giving, and (2) the estimation of the initial level of giving of nonitemizers. 


\subsection{The Price of Giving}

The price of giving is defined as the net cost to the taxpayer of a marginal increase in the charitable contribution. In the simple case of full deductibility, there would be a difference between this "last dollar price" and the price associated with the first dollar of giving only if the individual gives enough to change his marginal tax rate. For most taxpayers, and especially for those in the income classes that currently do not itemize, the level of giving is low enough that there would be little or no difference between the first and last dollar prices. When there is a difference, we use the last dollar price and adjust the income term for the effect of the difference between the marginal and inframarginal prices.

The difference between the first dollar price and the last dollar price is particularly important when there is a floor. In all cases, the simulation algorithim uses a procedure that converges on the marginal price that is consistent with the predicted level of giving.

In calculating the price of giving it is not enough to use the marginal tax rate that the individual faces on additional earnings. There are two reasons for this. First, a one dollar charitable gift and a one dollar decrease in earnings can affect the individual's tax liability differently for a number of reasons. The charitable gift can interact with the maximum tax on earned income and the deduction limitation while a change in earnings alters adjusted gross income and therefore the deductions and limits that depend on AGI. We avoid these problems by using the TAXSIM model to calculate explicitly the effect on the tax liability of a one dollar charitable gift. 21

21 To reduce rounding error problems, we actually calculate the effect of a ten dollar gift. 
The second problem is that individuals may contribute property as well as cash. When securities or other appreciated property is given to charity, the taxpayer deducts the market value of the assets and pays no tax on the capital gain. 22 To the extent that the taxpayer uses appreciated assets to make his gifts, this provision of the law reduces the cost of giving. Moreover, this aspect applies to nonitemizers as well as to itemizers.

There are three problems involved in reflecting gifts of appreciated property in the price variable: (1) What fraction of total giving takes the form of appreciated property? (2) What fraction of the value of the appreciated property is gain that would otherwise be taxed? and (3) What is the relevant effective tax rate? We follow the procedure used in the earlier econometric studies from which the price elasticity was derived. We calculate each taxpayers price as a weighted average of the price of cash gifts and the price (or cost) of gifts of appreciated property using as weights the average fractions of both types of gifts in the taxpayer's AGI class.23 If the taxpayer would otherwise have sold the contributed property immediately, the extra tax saving per dollar of gift associated with giving the property to charity is the product of

22 This is consistent with the general proposition that a gift of appreciated property does not constitute "recognition" of the gain and that the recipient of the property has the same basis as the donor. Since a charity is not taxed on its own capital gains, the carryover of the basis is irrelevant.

23 The fraction of total gifts that takes the form of property rises from about 3.5 percent for taxpayers with AGI's below $\$ 15,000$ to more than 70 percent for taxpayers with AGI's over $\$ 100,000$. 
the marginal tax rate on capital gains (mc) and the ratio of "gain" to value in the property that is contributed $(\mathrm{g} / \mathrm{v})$. Since the taxpayer also has the option of postponing the sale of the property or giving the property to another individual, the actual tax saving is less than $\operatorname{mc}(\mathrm{g} / \mathrm{v})$, say $\lambda \cdot \mathrm{mc} \cdot(\mathrm{g} / \mathrm{v})$. Although the capital gains tax rate $(\mathrm{mc})$ can be calculated explicitly for each individual, neither $\lambda$ nor $\mathrm{g} / \mathrm{v}$ is directly observable. In the previous econometric work (Feldstein and Clotfelter, 1976; Feldstein and Maylor, 1976), a maximum likelihood procedure was used to estimate the product $\lambda(\mathrm{g} / \mathrm{v})$ on the assumption that this was the same for all individuals. The maximum likelihood value of $\lambda(\mathrm{g} / \mathrm{v})=0.50$ is used in the current calculation. Of course, since our focus in this paper is on the low-and middle-income taxpayers who now do not itemize (or who would stop itemizing if a separate charitable deduction were allowed), gifts of appreciated property are relatively unimportant and any errors introduced by our approximation are likely to be very small.

\subsection{The Giving of Nonitemizers}

Although the tax return indicates the contributions of all taxpayers who itemized their deductions, no information is available about the contribution of nonitemizers under existing law. An initial value of giving, $G_{0 i}$, must be imputed to each nonitemizer before any of the calculations begin. This imputation is done by matching each nonitemizer to an"equivalent" itemizer and then assigning to the nonitemizer the itemizer's gift scaled down to reflect the price difference and any difference in income. 
More specifically, our imputation program read in parallel separate computer tapes for the nonitemizers and the itemizers. For each nonitemizer, the program looked at successive itemizers until a record was found with the same adjusted gross income class. The giving and the price of the itemizer, GI and $\mathrm{PI}$, were then used to calculate a trial value of giving for the nonitemizer (GN) according to the formula $G N=G I(P I / P N I)-\alpha(Y I / Y N I)-\beta$. This in effect assigns to the nonitemizer the level of giving that the "matched" itemizer would have made if he had not been allowed to deduct his contribution, with a further correction for the difference between their disposable incomes.

Of course, some itemizers only choose to itemize because they make large charitable gifts; without their charitable deduction, they would pay less tax as nonitmeizers. It would be wrong to include these individuals in the group of itemizers used to impute giving to nonitemizers since the imputed giving would be too high for a nonitemizer. We therefore deleted this group in the imputation process.

Despite this, our procedure can still impute to a nonitemizer a level of giving which is so high that, if he had made that contribution, he would have chosen to itemize. We therefore truncate the imputed giving by imposing the limit that the initial gift of a nonitemizer must not exceed the greater of the standard deduction reduced by 3 percent of AGI and $\$ 500$.

\section{The Basic Simulation Results}

This section presents the simulation results based on the traditional demand model of charitable giving. The analysis compares the implications of alternative price elasticities and examines the effects of two different floors below which non-itemized gifts are not deductible. 
All of the calculations refer to 1977. The proposed changes are regarded as modifications in the tax law as of 1977 and all dollar amounts are based on the sample of actual tax returns for 1977. The calculations are not forecasts of the short-mun effects of a legislative change but simulations of what 1977 might have looked like if the tax mles relating to charitable gifts had 'always' been different. 24

Table 1 describes the situation as it actually was in 1977 under the existing tax mules. 25 Approximately 23 million itemizers contributed a total of nearly $\$ 19$ billion. Since the tax returns contain no information about gifts by nonitemizers, their "actual" behavior in 1977 under existing tax mules must itself be estimated. This estimation procedure has already been described in section 3.2. The final four columns of Table 1 present estimates corresponding to four different price elasticities. It is clear that since most nonitemizers have rather low marginal tax rates, the choice among the price elasticity assumptions has relatively little effect on the estimated total giving by nonitemizers. The range of estimates is from $\$ 17.5$ billion to $\$ 19.7$ billion. Table 2 summarizes the aggregate effects of alternative ways of extending the charitable deduction to nonitemizers. These estimates include not only the response of those who were nonitemizers in 1977 but also the changes in taxes and in giving among itemizers who would switch to nonitemizer status if the tax rule were changed.

24 See Clotfelter (1980) on the difference between the long-run and the shortrun responses to changes in tax rates. The response to a permanent change in tax mules might however be more rapid than the response to transitory changes in tax rates.

25 Although these figures do not correspond exactly to published IRS numbers because we have used a sample of returns, the large size of the sample guarantees that errors are very small. 
Consider, for example, the effect of full deductibility with a price elasticity of -1.0 . The simulations imply that this would increase giving by $\$ 3.5$ billion and would reduce tax revenue by $\$ 4.0$ billion. For the nonitemizers alone, the price elasticity of 1.0 implies that the revenue loss would exactly equal the increase in giving. The excess of the revenue loss over the increased giving reflects the fact that previous itemizers who switch save substantially more in taxes than the increase, if any, in their giving. The "budgetary efficiency" estimate of 0.87 is the ratio of increased giving to reduced taxes implied by extending full deductibility to nonitemizers if the price elasticity is one.

A more realistic price elasticity of 1.3 implies a 29 percent higher level of increased giving but only 2 percent greater revenue loss. The budgetary efficiency value rises to 1.10 , implying that charities receive an additional \$1.10 for each extra dollar of revenue foregone by the Treasury. Limiting the deduction of gifts by nonitemizers to the excess over $\$ 300$ reduces both the revenue loss and the increased giving. With all these elasticities, the increase in giving is reduced by much less than the fall in revenue. With an elasticity of -1.3 , for example, the $\$ 300$ floor reduces the additional giving by $\$ 900$ million (from $\$ 4.506$ billion to $\$ 3.608$ billion) but reduces the tax loss by nearly twice as much from $\$ 4.101$ billion to $\$ 2.430$ billion, a decline of $\$ 1.7$ billion).

A floor equal to 3 percent of adjusted gross income instead of a flat $\$ 300$ has quite similar aggregate effects. With a price elasticity of -1.3 , giving falls $\$ 1.5$ billion (from $\$ 4.506$ billion to $\$ 3.039$ billion) while the tax loss is reduced by more than $\$ 2.1$ billion (from $\$ 4.101$ to $\$ 1.943$ ). Note that 


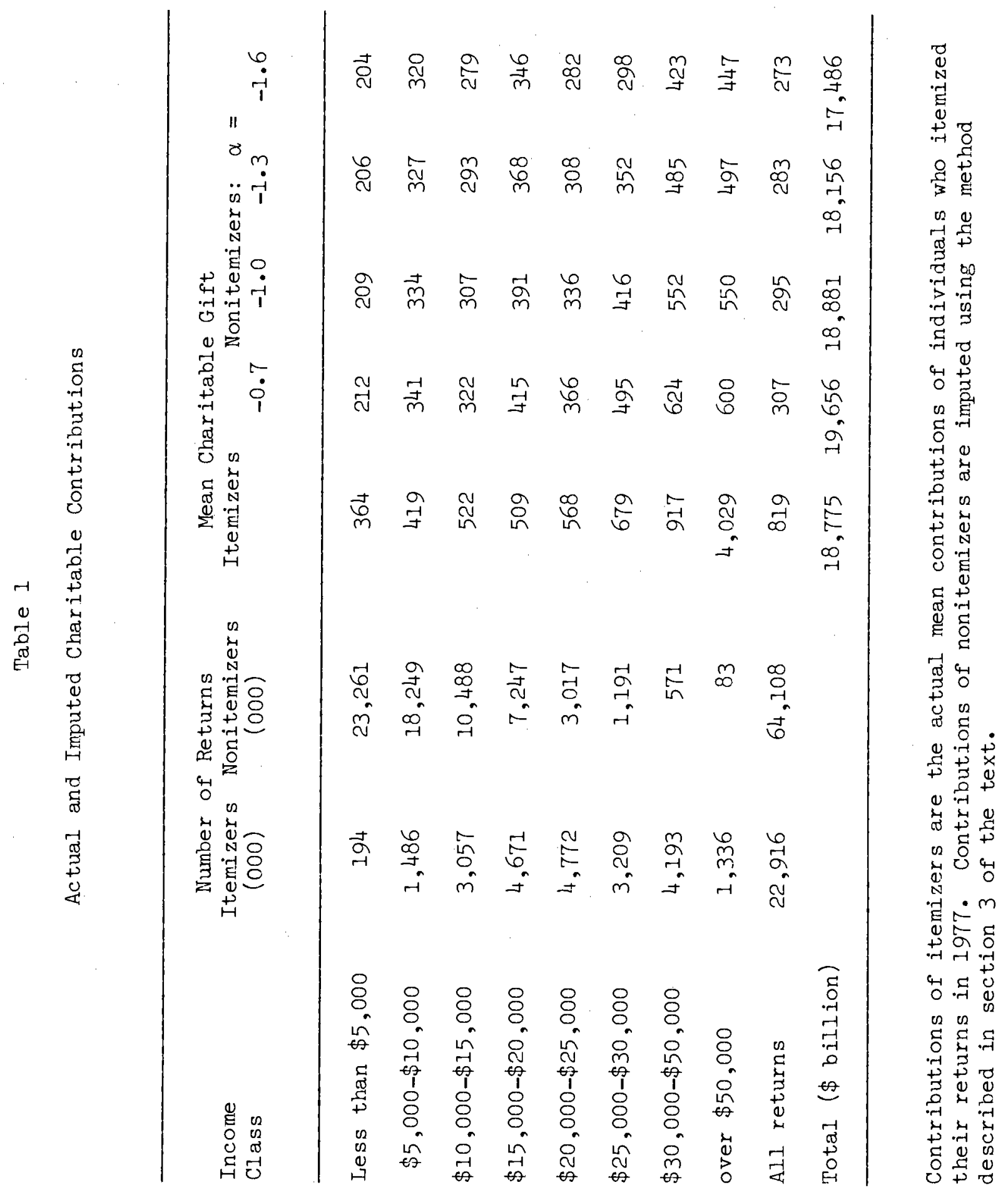




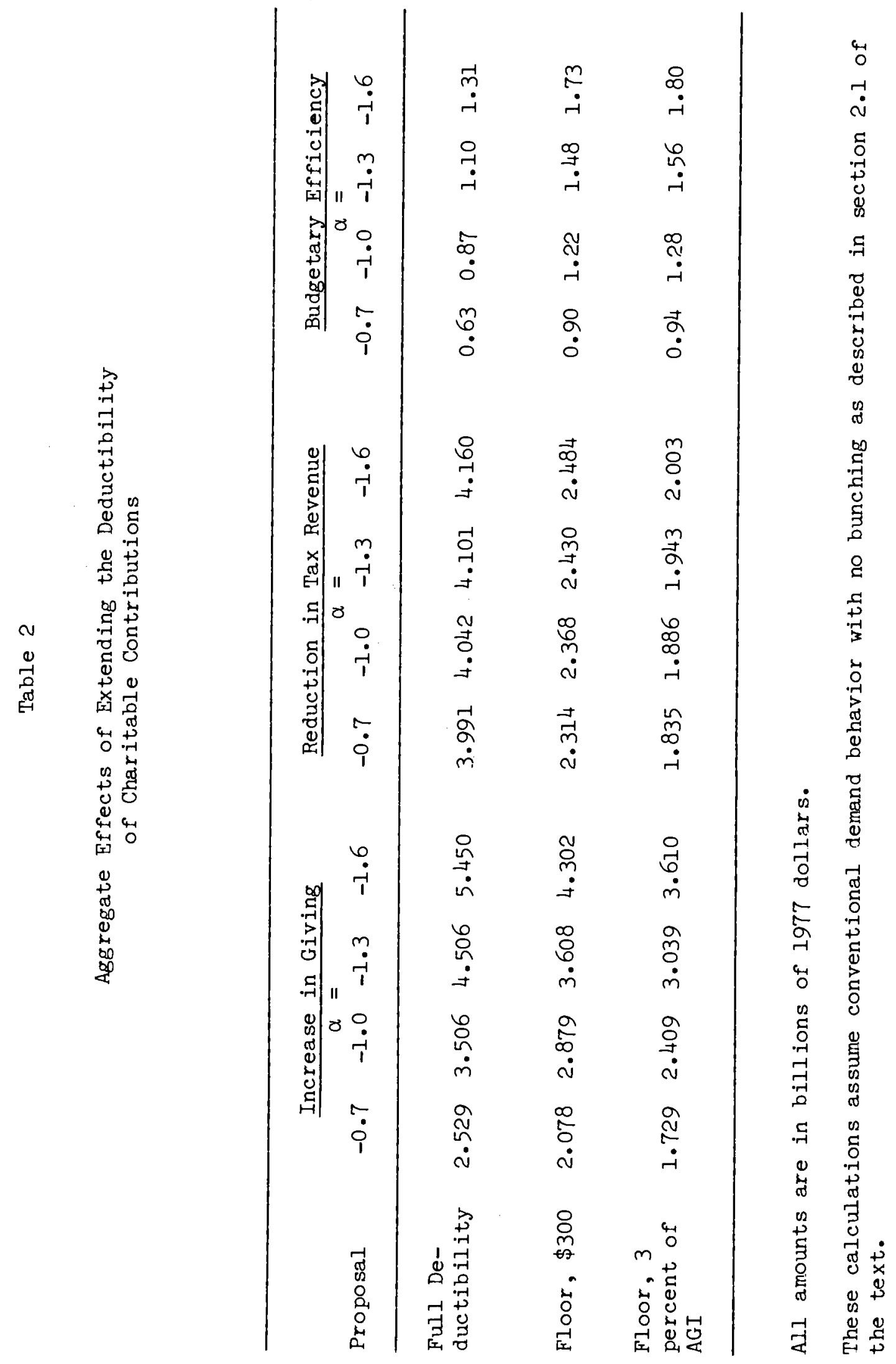


increasing the floor from $\$ 300$ to 3 percent of AGI actually reduces giving by more than the saving in taxes; total giving falls an additional $\$ 569$ million while the tax loss is cut by only $\$ 487$ million. The primary reason for this is that the effect of the percent-of-AGI floor is concentrated more on those taxpayers with high marginal tax rates for whom the relative reductions are large. Table 3 shows the changes in the mean giving and tax liabilities in each adjusted gross income class and, for reference, the initial levels of giving and tax liabilities. These figures combine itemizers and nonitemizers. All of the calculations are based on a price elasticity of -1.3 .

Consider, for example, taxpayers in the $\$ 10,000$ to $\$ 15,000$ adjusted gross income class. Of the 13.5 million taxpayers in this group, 10.5 million were nonitemizers in 1977. Extending full deductibility of charitable gifts to all taxpayers would cause giving to increase by an average of $\$ 74$ and taxes to fall by an average of $\$ 63$. A $\$ 300$ floor would reduce this increase in giving by $\$ 20$ but would lower the fall in taxes by $\$ 30$. Raising the floor to 3 percent of AGI instead of $\$ 300$ would reduce giving by an average of $\$ 5$ and would save an average of $\$ 4$ in taxes.

Note that full deductibility has its maximum effect on the giving and taxes per return at the income levels between $\$ 15,000$ and $\$ 20,000$. Below $\$ 10,000$, the relatively low marginal tax rates provide less incentive while above $\$ 20,000$ the majority of taxpayers already itemize their deductions. Imposition of a $\$ 300$ floor would have virtually no effect on giving by taxpayers with AGI's over $\$ 25,000$ since most such taxpayers would give more than $\$ 300$ if deductibility were allowed. The absolute effect of the $\$ 300$ floor on the mean level of giving is also greatest among taxpayers with incomes between 
Table 3

Distribution of Changes in Mean Contributors and Tax Liabilities by Income Class

\begin{tabular}{|c|c|c|c|c|c|c|c|c|c|}
\hline \multirow[b]{3}{*}{$\begin{array}{l}\text { AGI } \\
\text { Class }\end{array}$} & \multirow{3}{*}{$\begin{array}{c}\text { Number } \\
\text { of } \\
\text { Returns } \\
(000)\end{array}$} & \multicolumn{8}{|c|}{ Increases in Giving and Reductions in Taxes } \\
\hline & & \multicolumn{2}{|c|}{$\begin{array}{c}\text { Initial } \\
\text { Levels }\end{array}$} & \multicolumn{2}{|c|}{$\begin{array}{c}\text { Full Deducti- } \\
\text { bility }\end{array}$} & \multicolumn{2}{|c|}{$\$ 300$ Floor } & \multirow{2}{*}{$\begin{array}{l}3 \% \text { AGI } \\
\text { Giving }\end{array}$} & \multirow{2}{*}{$\begin{array}{l}\text { Floor } \\
\text { Tax }\end{array}$} \\
\hline & & Giving & $\operatorname{Tax}$ & Giving & $\operatorname{Tax}$ & Giving & Tax & & \\
\hline Less than $\$ 5,000$ & 23,455 & 208 & 11 & 5 & 5 & 5 & 3 & 4 & 4 \\
\hline$\$ 5,000-\$ 10,000$ & 19,735 & 334 & 437 & 61 & 54 & 46 & 32 & 52 & 35 \\
\hline$\$ 10,000-\$ 15,000$ & 13,545 & 344 & 1,206 & 74 & 63 & 54 & 33 & 49 & 29 \\
\hline$\$ 15,000-\$ 20,000$ & 11,918 & 423 & 2,078 & 93 & 84 & 80 & 52 & 65 & 38 \\
\hline$\$ 20,000-\$ 25,000$ & 7,789 & 467 & 3,026 & 61 & 59 & 49 & 32 & 29 & 18 \\
\hline$\$ 25,000-\$ 30,000$ & 4,399 & 591 & 4,274 & 61 & 57 & 50 & 34 & 26 & 16 \\
\hline$\$ 30,000-\$ 50,000$ & 4,763 & 865 & 6,879 & 50 & 50 & 46 & 35 & 24 & 15 \\
\hline Over $\$ 50,000$ & 1,419 & 3,818 & 29,130 & 75 & 70 & 72 & 60 & 40 & 20 \\
\hline All Returns & 87,024 & 424 & 1,913 & 52 & 47 & 41 & 28 & 35 & 22 \\
\hline $\begin{array}{l}\text { Total } \\
\text { (\$ billion) }\end{array}$ & 87.024 & 36.931 & 166.456 & 4.506 & 4.101 & 3.608 & 2.430 & 3.039 & 1.943 \\
\hline
\end{tabular}

All calculations are based on a price elasticity of -1.3 and refer to all taxpayers, including both current itemizers and nonitemizers. 
$\$ 10,000$ and $\$ 20,000$. By contrast, a floor equal to 3 percent of AGI has a very substantial effect on the gifts and taxes of relatively high income taxpayers. A 3 percent floor virtually eliminates any tax saving for those with incomes over $\$ 25,000$. Although total giving is lower with a 3 percent of AGI floor than with a $\$ 300$ floor, giving by the large number of taxpayers with incomes under $\$ 10,000$ is slightly higher.

Although table 2 suggests that a floor would be an "efficient" way of modifying the extension of the charitable deduction to all taxpayers (in the sense that it saves substantially more tax revenue than it reduces charitable giving), table 3 indicates that a floor would also significantly change the distribution among income classes of both the increased giving and the reduced tax liability. Similarly, table 3 makes it clear that the choice between a $\$ 300$ floor and a 3 percent of AGI floor involves not only aggregate efficiency considerations but also the income class distribution of the changes in giving and in tax liabilities. Of course, differences in the income class distribution of giving has significant effects on the types of charities that benefit.

\section{Simulating Nonstandard Behavior}

All of the calculations in section 4 were based on the conventional static utility maximization model of consumer demand for charitable giving. The more dynamic assumption that taxpayers respond to a floor by bunching contributions over time will be examined in the current section. The more radical departure from conventional utility maximization, the net altruism model of charitable giving, will also be considered. 


\subsection{Bunching}

Any floor on the charitable deduction would provide taxpayers with an incentive to "bunch" their charitable contributions, giving a high level of contributions in some years and a low level in others. Because the existing law does not contain such a floor, we have no evidence about the likely extent of bunching. This section therefore presents simulation results for a rather broad range of two-year bunching assumptions. The restriction to a two-year cycle is significant and should be borne in mind in considering the results. All of the simulations refer to a price elasticity of -1.3 .

When a taxpayer responds to a floor by bunching his contributions, he reduces the amount of his giving that is not deductible and thereby increases the tax saving associated with any level of giving. Moreover, to the extent that annual unbunched giving would be less than the floor while bunched giving exceeds the floor, the process of bunching also reduces the marginal price of giving and thus encourages increased giving. These two effects apply to both the "total bunching" and "partial bunching" models described in section 2.

Recall that, with the total bunching model, the probability that individual $i$ will bunch is given by

$$
\mathrm{PROB}_{i}=1-\left(\mathrm{BCG}_{1 i} / \mathrm{CG}_{1 i}\right)^{\rho}
$$

where $\mathrm{CG}_{1} i$ is the net cost to taxpayer $i$ of giving the amount that he would choose to give in the presence of a floor if he does not bunch and $\mathrm{BCG}_{1 \mathrm{i}}$ is the net cost of giving that amount with bunching. Table 4 presents simulation results with four different values of the bunching sensitivity variable. The striking feature of the results in this table is that bunching appears to have only a very modest effect on both tax revenue and giving. For 


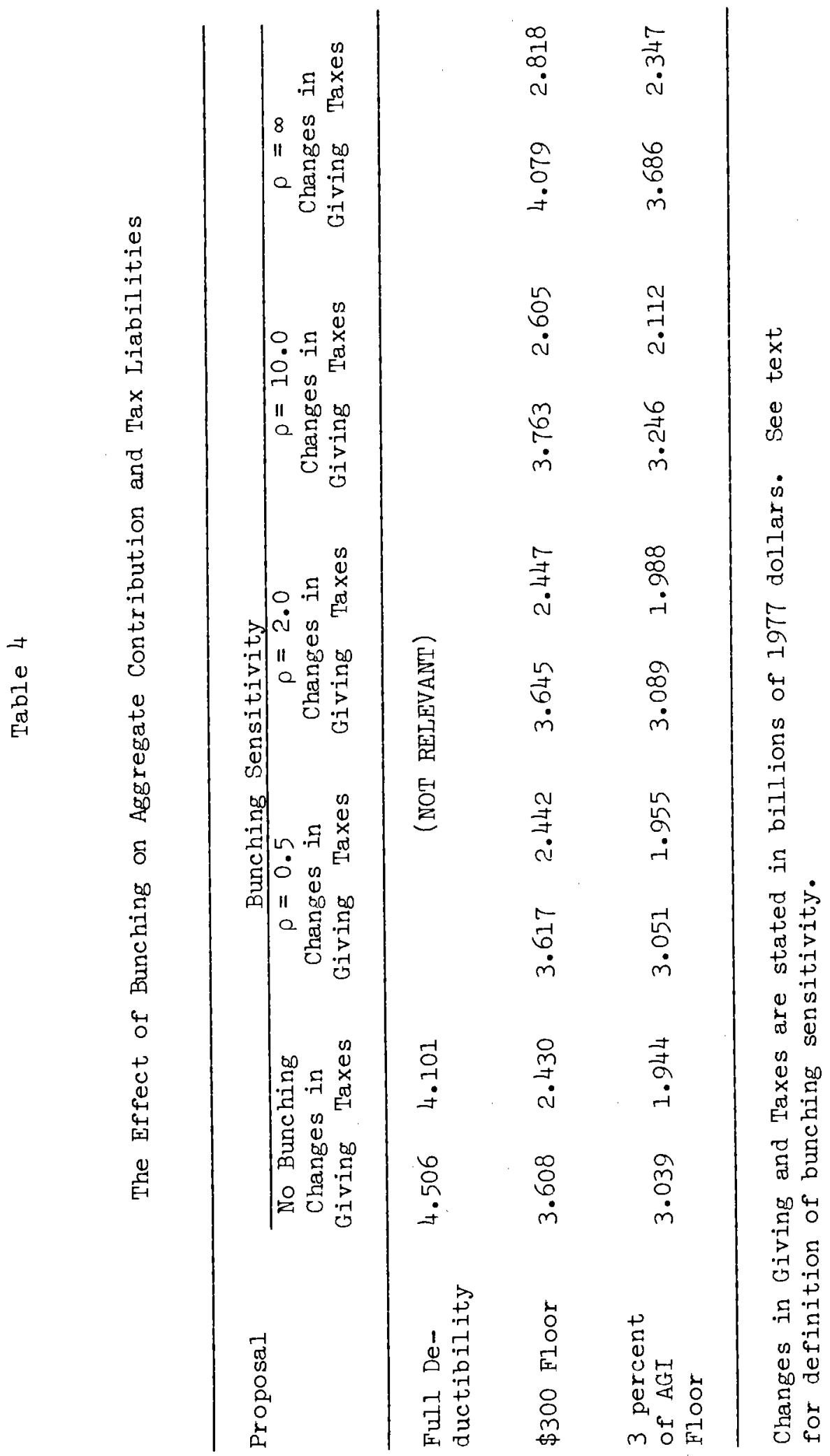


example, a $\$ 300$ floor with no bunching reduces giving by $\$ 898$ million, from $\$ 4.506$ billion to $\$ 3.608$ billion. With the bunching described by the moderate sensitivity value of $\rho=2$, the decline in giving is reduced from $\$ 898$ million to $\$ 861$ million. Even with the high sensitivity value of $\rho=10$, giving is still reduced by $\$ 743$ million. Indeed, even the limiting case in which everyone who can benefit from bunching does bunch still leaves the extra giving $\$ 427$ million lower than without a floor.

The effect of bunching on tax revenue is limited in a similar way. Without bunching, the $\$ 300$ floor reduces the revenue loss by $\$ 1.671$ billion, from $\$ 4.101$ billion to $\$ 2.430$ billion. Even with the high sensitivity value of $\rho=10$, the $\$ 1.671$ billion revenue effect of the floor is reduced by only $\$ 175$ mililion. This very small effect of bunching on the revenue loss reflects the distribution of gifts by non-itemizers, particularly the large number of relatively small gifts for which the floor would eliminate all or nearly all deductibility. An individual who would give less than $\$ 150$ a year without bunching would get no deduction even if he bunched completely. And a taxpayer who gives $\$ 400$ every other year instead of $\$ 200$ each year still gets a deduction for only one-fourth of his total giving.

Table 5 presents results for the "partial bunching" model in which all taxpayers who can benefit from bunching do bunch at least part of their gift. The results are similar to the probabilistic total bunching model of Table 4 but indicate even smaller effects on giving and tax revenue. 26

Since there is no experience with floors on which to base empirical estimates of the taxpayers' likely response, it is reassuring that the results

26 The figures for full and partial bunching with $\rho=\infty$ would be exactly equal if there were no gifts of appreciated property. The small difference in our calculations reflects differences in the assumed realization of capital gains. 


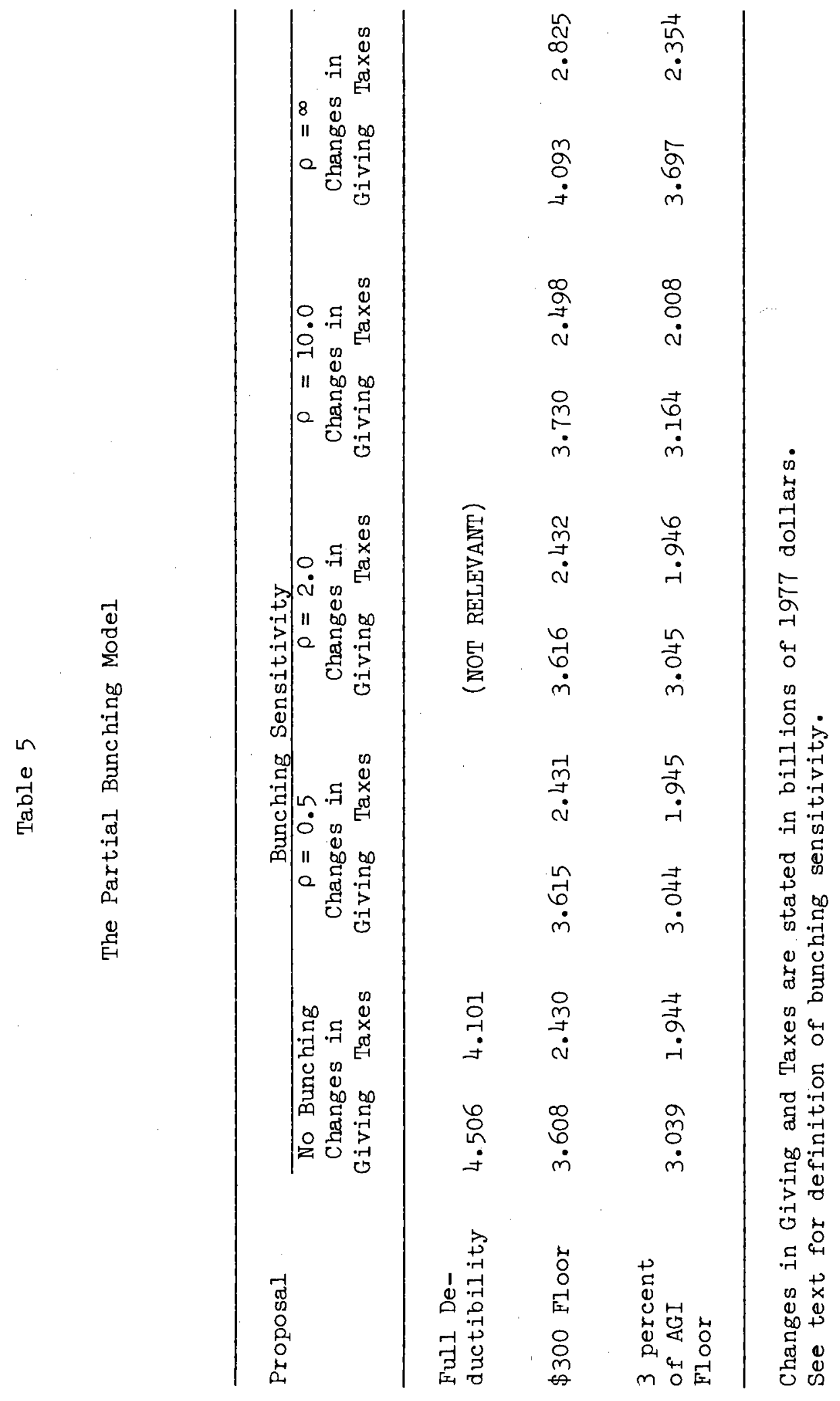


of this section are not sensitive to a wide variation in assumptions about the possible extent of bunching. It should, however, be borne in mind that only two-year bunching was considered and that if taxpayers bunched over a longer period the effects would be more substantial.

\subsection{Net Altruism}

The "net altruism" model of charitable giving described in section 2.3 implies that individuals choose the amount that they contribute to charity to achieve a desired net cost to themselves. Individual differences in the desired net cost reflect differences in income and taste. Alternative tax rules affect charitable giving by altering the amount that individuals can contribute per dollar of net cost. Any loss in tax revenue is matched by an equal increase in charitable giving.

In the simple context of extending the charitable deduction without any floor, net altruism is equivalent to a price elasticity of minus one for the nonitemizers themselves. However, net altruism implies that the taxpayers who switched from itemizing to using the standard deduction will add the resulting tax saving to their charitable gifts. Moreover, where giving causes a reduction in marginal tax rates, the net altruist contributes all of the intramarginal tax saving while traditional demand behavior implies that intramarginal saving has only a small income effect. The difference between the conventional demand model with unitary price elasticity and the net altruism nodel is shown in the first row of table 6 .

The contrast between conventional demand and net altruism is much greater when there are floors. Table 6 shows that the conventional demand model with a unitary price elasticity implies that a $\$ 300$ floor causes giving 
Table 6

The Effect of Net Altruism Behavior

on Aggregate Contributions and Tax Liabilities

\begin{tabular}{|c|c|c|c|c|c|c|}
\hline \multirow[t]{2}{*}{ Proposal } & \multicolumn{3}{|c|}{$\begin{array}{c}\text { Conventional Demand } \\
\text { with } \alpha=-1\end{array}$} & \multicolumn{3}{|c|}{ Net Altruism } \\
\hline & $\begin{array}{l}\text { Change: } \\
\text { Giving }\end{array}$ & $\begin{array}{l}3 \text { in } \\
\text { Taxes }\end{array}$ & $\begin{array}{l}\text { Budgetary } \\
\text { Efficiency }\end{array}$ & $\begin{array}{l}\text { Changes } \\
\text { Giving }\end{array}$ & $\begin{array}{l}\text { in } \\
\text { Taxes }\end{array}$ & $\begin{array}{l}\text { Budgetary } \\
\text { Efficiency }\end{array}$ \\
\hline $\begin{array}{l}\text { Full De- } \\
\text { ductibility }\end{array}$ & 3.506 & 4.042 & 0.867 & 3.871 & 3.951 & 0.979 \\
\hline$\$ 300$ Floor & 2.879 & 2.368 & 1.216 & 1.963 & 2.008 & 0.978 \\
\hline $\begin{array}{l}3 \text { percent } \\
\text { of AGI } \\
\text { Floor }\end{array}$ & 2.409 & 1.886 & 1.277 & 1.543 & 1.573 & 0.980 \\
\hline
\end{tabular}

Changes in Giving and Taxes are stated in billions of 1977 dollars. See text for definition of bunching sensitivity. 
to fall by $\$ 600$ million and increases tax revenue $\$ 1.7$ billion. With net altruism, the reduced deductibility has a much bigger effect on giving. Giving falls by $\$ 1.9$ billion and the tax revenue rises by an equal amount. The results are similar if the floor is stated as a percent of adjusted gross income. If the net altruism model is true, extending the deduction with a floor does not have greater budgetary efficiency than full deductibility. Introducing the floor in itself no longer increases tax revenue by more than it reduces giving. With net altruism, the principal reason for having a floor is to reduce the scale and cost of extending deductibility. The floor would of course also affect the income class distribution of the induced changes in giving and tax payments and therefore the mix of donees that benefit.

The choice between the net altruism model and the conventional demand model cannot be settled decisively with the available evidence. To the extent that the estimated price elasticity is significantly different from minus one, the data do support a conventional demand analysis. But it is quite possible that some individuals behave according to net altruism principles while the behavior of others is best described by a conventional demand analysis. If so, the observed price elasticity is a misleading guide to what would happen if deductibility were extended with a floor. The results would then be some mix between the net altruism behavior of Table 6 and the conventional demand response with a price elasticity between -1.3 and -1.6 .

\section{Concluding Remarks}

The primary purpose of the present paper is methodological: to examine how tax simulation could be extended to incorporate nonlinear budget constraints and nonstandard economic behavior. We have shown how econometric 
estimates derived under existing tax mules can be exended to deal with this wider range of simulations. On those issues for which existing evidence is not informative we have presented simulation that indicate the sensitivity of the conclusion to the unknown aspects of behavior.

The specific simulations indicate that the econometric evidence on charitable giving implies that extending the charitable deduction to nonitemizers would raise individual giving by about 12 percent of the existing total amount or $\$ 4.5$ billion at 1977 levels. The extension would reduce tax revenue by slightly less, about $\$ 4.1$ billion. A floor of $\$ 300$ or 3 percent of AGI would reduce the revenue loss by 30 to 40 percent, even if there is significant bunching. The effect of the floor on increased giving depends critically on whether taxpayers' behavior is guided by conventional demand principles or by the net altruism rule. A reasonable conclusion is that a floor would reduce giving by less than the increased revenue but that the difference between them would not be very large.

In conclusion, it should perhaps be stressed that the appropriate tax treatment of charitable contributions depends on much more than the effects of alternative tax rules on the magnitude and distribution of contributions and taxes. Andrews (1972), for example, has argued that a correct definition of net income requires deducting charitable gifts while Surrey (1973) has argued the opposite. Feldstein (1980) has emphasized that a tax subsidy of individual giving may be preferable to goverment spending for the same purpose even when a dollar of tax revenue loss induces less than a dollar of additional giving if individual giving is influenced by the level of government spending on the particular activity. Still others have emphasized the administrative and 
compliance problems associated with extending the deduction to low income taxpayers who are rarely audited. All these considerations are important but lie beyond the scope of the current paper. 


\section{Bibliography}

Andrews, William D. December 1972. Personal deductions in an ideal income tax, Harvard Law Review 86: 309-385.

Boskin, Michael J. and Martin Feldstein. August 1977. Effects of the charitable deduction on contributions by low-income and middle-income households: Evidence from a national survey of philanthropy," Review of Economics and Statistics 59: 351-354.

Clotfelter, Charles T. 1980. Tax incentives and charitable giving: Evidence from a panel of taxpayers," Journal of Public Economics 13: 319-340.

Clotfelter, Charles T, and Steuerle, C. Fugene. 1979. The effect of the federal income tax on charitable giving. Forthcoming. Duke University and Office of Tax Analysis.

Dye, Richard F. 1977. Personal charitable contributions: Tax effects and other motives. Proceedings of the National Tax Association.

Feldstein, Martin. 1975a. The income tax and charitable contributions: Part I - aggregate and distributional effects. National Tax Journal 28: 81-100. - 1975b. The income tax and charitable contributions: Part II - the impact on religious educational, and other organizations. National Tax Journal 28: 209-226.

- 1980. A contribution to the theory of tax expenditures: the case of charitable giving. In Aaron, $H$ and Boskin, M., eds. Essays in Honor of Joseph Pechman. Washington, D.C.: The Brookings Institution. 
Feldstein, Martin and Clotfelter, Charles. 1976. Tax incentives and charitable contributions in the United States. Journal of Public Economics 5: 1-26.

Feldstein, Martin and Taylor, Amy. 1976. The income tax and charitable contributions. Econometrica 44: 1201-1222.

Hausman, Jerry A. 1979. Exact consumer's surplus. Massachusettes Institute of Technology. Mimeo.

Reece, William S. 1979. Charitable contributions: New evidence on household behavior. American Economic Review 69: 142-151.

Surrey, Stanley S. 1973. Pathways to tax reform Cambridge: Harvard University Press. 